\title{
The protective effect of North Schisandra Lignans on vascular endothelial cell oxidation injuries
}

\author{
Ruowen Zhang ${ }^{\mathrm{a}}$, Yilin Wang ${ }^{\mathrm{b}}$, Dong Zhu ${ }^{\mathrm{c}}$, Fengying Dong ${ }^{\mathrm{d}}$ and Xi Chen ${ }^{\mathrm{e}, *}$ \\ ${ }^{a}$ Beihua University Faculty of Medicine, Beihua University, Jilin, China \\ ${ }^{\mathrm{b}}$ The First Clinical Medical College, Beijing University of Chinese Medicine, Beijing, China \\ ${ }^{\mathrm{c}}$ The Second Clinical Medical College, Guangzhou University of Chinese Medicine, Guangzhou, \\ Guangdong, China \\ d Jilin Gynecology and Obstetrics Hospital, Jilin, China \\ ${ }^{\text {e } P a t h o g e n ~ B i o l o g y}$ Department, College of Basic Medicine, Beihua University, Jilin, China
}

\begin{abstract}
.
BACKGROUND: In this study, the authors cultivated ECV-304 in vitro and incubated cells with $\mathrm{H}_{2} \mathrm{O}_{2}$, established injury models, and induced oxidized endothelial cell apoptosis. This model makes it possible to choose suitable concentrations of North Schisandra Lignans.

OBJECTIVE: To study the protective effects of North Schisandra Lignans on human umbilical vein endothelial cell injuries. METHODS: Endothelial cell growth and proliferation activity were detected through the MTT method. The colorimetric method was used to determine superoxide dismutase (SOD) activity in the cell culture solution, as well as malondialdehyde (MDA) content in the cell.

RESULTS: North Schisandra Lignans noticeably decreased ECV-304 cell injury induced by $\mathrm{H}_{2} \mathrm{O}_{2}$. Moderate and high concentrations of North Schisandra Lignans could significantly lower MDA content and heighten SOD activity. These differences were significant compared to the $\mathrm{H}_{2} \mathrm{O}_{2}$ group $(P<0.05)$.

CONCLUSIONS: North Schisandra Lignans had an obvious protective effect on ECV-304 injured by $\mathrm{H}_{2} \mathrm{O}_{2}$. The mechanism decreases MDA production and heightened SOD activity.
\end{abstract}

Keywords: North Schisandra Lignans, vascular endothelial cell, superoxide dismutase, malondialdehyde

\section{Introduction}

Atherosclerosis (As) is a common cardiovascular disease that relates to vascular endothelial cell injury (VEC) $[1,2]$. The feature of As is the pathological change of involved arterial is usually from tunica intima and combined with multiple changes such as local accumulation of lipid and complex carbohydrate, fibrous tissue hyperplasia, calcium deposit, artery medial lysis, the secondary pathological changes also includes plaque entorrhagia, rupture and local thrombopoiesis [3]. Other arteriosclerosis pathological

\footnotetext{
${ }^{*}$ Corresponding author: Xi Chen, Pathogen Biology Department, College of Basic Medicine, Beihua University, Jilin, China. E-mail: chenxixinyue@aliyun.com.
} 
changes revealed by modern Cellular and Molecular Biology include macrophages vagile, smooth muscle cellular proliferation, quantity collagen fibers, elastic fibers and proteoglycans form into connective tissue matrix, lipid accumulates in or out cells [4,5]. Vascular endothelial cellular oxidative damage is considered to be an initiating agent of As.

Endothelial dysfunction often plays an important role in diseases such as As [9] and hypertension [6]. As the main accommodator of hemal dynamic balance, vascular endothelial cells can inhibit vascular smooth muscle cellular growth by expanding blood vessels and inhibiting inflammatory reactions to protect blood vessels. These effects are mainly mediated by NO, which is the most efficient endogenous vasodilating agent synthesized by NOS. NO can inhibit low density lipoprotein oxidation [7]. Evidence has shown that endothelial dysfunction, which can be detected by opacification or ultrasonic testing before vessel wall structure change occurs [8], is the prophase marker of As. Along with the deeply study on the mechanism of vascular endothelium injury, oxidative stress is more and more concerned. Oxygen radicals mediate oxidative stress, called active oxide (ROS). ROS-caused oxidative stress can lead to As. Besides oxidative stress, the signal passageway mediated by active oxygen may relate to monocytic adhesion and imbibition, thrombocytic activation, and contractile fiber cellular migration, which occurs in As $[9,10]$.

Studies have shown that North Schisandra Lignans has obvious anti-oxidant effects. According to recent empirical studies and clinical trials, North Schisandra Lignans separated from Schisandra chinensis prevents atherogenesis by inhibiting oxidative low density lipoprotein, endothelial cells and monocyte adhesion, contractile fiber cellular immigration and proliferation, and macrophages cholesterol accumulation. It also promotes inflammatory cytokines and platelet aggregation expression $[17,18]$ to protect the heart [11]. North Schisandra Lignans also have anti-oxidative stress protective effects on diabetics [12].

\section{Material}

\subsection{Cell strain}

HUVEC (ECV-304) was supplied by Jiang Su University.

\subsection{Reagents}

North Schisandra Lignans were supplied by Shanghai Vinhaket Biotechnology Co., Ltd, at $4-5^{\circ} \mathrm{C}$ iced storage. DMEM, EDTA, Trypsin, DMSO, MTT, acrylamide, glycine, and SDS were from American Sigma Co., LTD. Newborn calf serum, SOD kit, MDA kit, methylene bisacrylamide, and Tris were from American Amresco Co., LTD. Ammonium persulfate, TEMED, and PVDF were from American Promega Co., LTD. iNOSâ-actin antibody, IgG antibody marked by peroxidase, and NO kit were from American SantaCruz Co., LTD.

\subsection{Instruments}

Gel Doc XR gel imagery analytical system (Bio-Rad, American); SG ultrapure water machine (Germany); ELISA (RT-2100C, American); $-70^{\circ} \mathrm{C}$ ultra cold freezer (HOF-382, Japan); Olympus inverted phase contrast microscope (IX70, Japan); $\mathrm{CO}_{2}$ incubator (Shel-lab Co., LTD.); Western blot transmembrane machine (Bio-Rad, American). 


\section{Methods}

\subsection{Cell culture and grouping}

ECV-304 cells were cultured in $15 \%$ fetal calf serum DMEM, $37^{\circ} \mathrm{C}, 5 \% \mathrm{CO}_{2}$, and $0.25 \%$ trypsinase digestive. There was one generation every $2 \mathrm{~d}$. Exponential phase cells were used in the next experiment. The cells were divided into four groups: control group, discard pro-media, add $10 \%$ fetal calf serum DMEM, culture for $24 \mathrm{~h} ; \mathrm{H}_{2} \mathrm{O}_{2}$ group, add $1 \mathrm{mmol} / \mathrm{L} \mathrm{H}_{2} \mathrm{O}_{2}$ into $10 \%$ fetal calf serum DMEM; three different concentration drug groups, $30 \mathrm{~min}$ before adding $1 \mathrm{mmol} / \mathrm{L}_{2} \mathrm{O}_{2}$, add $15 \mathrm{mg} / \mathrm{L}, 30 \mathrm{mg} / \mathrm{L}$, $60 \mathrm{mg} / \mathrm{L}$ North Schisandra Lignans, further culture for $24 \mathrm{~h}$. Cells and supernatant fluids were collected; the morphologic changes of every group were observed under an inverted phase contrast microscope. The MTT method was used to test cellular activity. We then detected the MDA, SOD, and NO content of each group's cellular supernatant fluid. Set six double-pored each group. Each experiment was repeated three times.

\subsection{The MTT colorimetric method to assess cell viability}

Exponential phase ECV-304 cells $\left(1 \times 10^{8} / \mathrm{L}\right)$, vaccinate on 96-wells cell culture plate, add $100 \mu \mathrm{L}$ unicell suspension each hole, culture for $24 \mathrm{~h}$ in $\mathrm{CO}_{2}$ incubator, deal with the cells after adherence, $6 \sim 8$ double-pored each group. $24 \mathrm{~h}$ later, $18 \mu \mathrm{L}(5 \mathrm{~g} / \mathrm{L})$ of MTT was added into each hole; they were incubated for $4 \mathrm{~h}$ at $37^{\circ} \mathrm{C}$. Supernatant fluid was softly sucked away and discarded. $150 \mu \mathrm{L}$ of DMSO was added to each hole; they were agitated for $15 \mathrm{~min}$ to thoroughly dissolve the blue crystals. A $490 \mathrm{~nm}$ wave length was used to determine the OD. The cell multiplication inhibition ratio was calculated according to the OD. The Inhibition ratio(\%) $=(1-$ drug group OD/116001control group OD) $\times 100 \%$.

\subsection{MDA content detection}

The penthiobarbital acid coloration method was applied. The procedure was completed according to the MDA kit's instruction manual. $100 \mu \mathrm{L}$ cellular culture solution, $532 \mathrm{~nm}$ detect the absorbance, calculate MDA content according to formula. MDA content $(\mu \mathrm{mol} / \mathrm{L})=($ determined tube absorbance determined blank tube absorbance)/(standard tube absorbance - standard blank tube absorbance $) \times$ proof sample concentration + dilution multiple of sample before detection.

\subsection{SOD content detection}

The Xanthine oxidase method was applied. The procedure was conducted according to the SOD kit's instruction manual. $100 \mu \mathrm{L}$ cellular culture solution, $550 \mathrm{~nm}$ detect the absorbance, calculate SOD content according to formula. SOD content $(\mu \mathrm{mol} / \mathrm{L})=($ control tube absorbance - determined tube absorbance)/control tube absorbance $/ 50 \%$ dilution multiple of reaction system $\times$ dilution multiple of sample before detection.

\subsection{NO content detection}

The Nitrate reductase method was applied. The procedure was conducted according to the NO kit's instruction manual. $1 \times 10^{5}$ vaccinated cells per hole were placed into 24 wells on a culture plate (4 wells per group), grouping and dealing like above. Ending culture later, collect each group's supernatant fluid $100 \mu \mathrm{L}, 550 \mathrm{~nm}$ detect the absorbance, calculate NO secretory. 
S654 R. Zhang et al. / The protective effect of North Schisandra Lignans on vascular endothelial cell oxidation injuries

Table 1

Effect of North Schisandra Lignans on ECV-304 cellular activity. $(n=3, \bar{x} \pm s)$

\begin{tabular}{lccc}
\hline Groups & Dose & \multicolumn{1}{c}{ OD } & Inhibition ratio (\%) \\
\hline Control group & - & $0.689 \pm 0.043$ & - \\
$\mathrm{H}_{2} \mathrm{O}_{2}$ group & - & $0.314 \pm 0.025^{* *}$ & $55.5211 \pm 4.126$ \\
North Schisandra Lignans group & $15 \mathrm{mg} / \mathrm{L}$ & $0.413 \pm 0.045$ & $32.589 \pm 2.541$ \\
& $30 \mathrm{mg} / \mathrm{L}$ & $0.569 \pm 0.065^{\#}$ & $17.354 \pm 1.365^{\#}$ \\
& $60 \mathrm{mg} / \mathrm{L}$ & $0.702 \pm 0.072^{\# \#}$ & $8.563 \pm 0.896^{\# \#}$ \\
\hline
\end{tabular}

${ }^{* *}$ Compared with control group, $P<0.01$; ${ }^{\#}$ Compared with $\mathrm{H}_{2} \mathrm{O}_{2}$ group, $P<0.05$. ${ }^{\# \#}$ Compared with $\mathrm{H}_{2} \mathrm{O}_{2}$ group, $P<$ 0.01 .

\subsection{Western blot}

Cell groups were collected, protein was extracted, and protein concentration was detected via the Bradford method. $8 \%$ polyacrylamide gel was used and 30 ìg of protein was added per swimming lane; the electrophoresis pressure was $120 \mathrm{~V}$ for $90 \mathrm{~min}$. A damp-dry transfer method was used to transfer the protein in the separation gel to the PVDF membranes. 5\% evaporated skimmed milk TBS-T buffer (25 mM Tris, $150 \mathrm{mM} \mathrm{NaCl}, 1 \%$ Tween 20, pH7.5), shaking $1 \mathrm{~h}$, blocking non-specificity sites on PVDF membrane. The PVDF membrane was washed with a Tris buffer 3 times 10 min each time. Ab was added (1:1000 diluted) and kept at $4{ }^{\circ} \mathrm{C}$ overnight. On the second day, a second $\mathrm{Ab}$ dilution (1:2000 diluted) and membrane were incubated at room temperature for $1 \mathrm{~h}$ and washed 3 times with TBS-T on a swing bed, $10 \mathrm{~min}$ each time, do chemoluminescence reaction, â-actin as internal reference. The results were collected with a gelatin imaging system and grayscale value detection was performed. The ratio between the sample's protein strap grayscale value and the â-actin was considered to be relevant for protein expression relative amount.

\section{Statistics}

The data was indicated as $\bar{x} \pm s$. SPSS 13.0 software was used to analyze the results. The variance analysis proceeded according to One Way-ANOVA. Comparison apply Student' T test, $P<0.05$ stands for significant difference.

\section{Results}

\subsection{The effect of North Schisandra Lignans on ECV-304 cellular activity}

Treated by $\mathrm{H}_{2} \mathrm{O}_{2}$, vascular endothelial cellular activity decreased noticeably compared with the control group; the difference was significant $(P<0.01)$. The cellular fractional inhibition rate went up to $54 \%$. Adding $15 \mathrm{mg} / \mathrm{L}, 30 \mathrm{mg} / \mathrm{L}$, or $60 \mathrm{mg} / \mathrm{L}$ North Schisandra Lignans in advance improved vascular endothelial cellular activity and decreased the $\mathrm{H}_{2} \mathrm{O}_{2}$ treated cellular inhibition ratio. Moderate and high North Schisandra Lignans concentration $+\mathrm{H}_{2} \mathrm{O}_{2}$ displayed significant differences compared with the $\mathrm{H}_{2} \mathrm{O}_{2}$ group $(P<0.05, P<0.01)$; the cellular activity of the high concentration drug group approached that of the control group, as shown in Table 1.

\subsection{Effect of North Schisandra Lignans on ECV-304 cellular supernatant fluid MDA and SOD content}

$24 \mathrm{~h}$ after being treated by $\mathrm{H}_{2} \mathrm{O}_{2}$, ECV-304 cellular supernatant fluid MDA content increased ob- 
R. Zhang et al. / The protective effect of North Schisandra Lignans on vascular endothelial cell oxidation injuries S655

Table 2

Effect of North Schisandra Lignans on ECV-304 cellular supermatant fluid MDA and SOD content. $(n=3, \bar{x} \pm s)$

\begin{tabular}{lccc}
\hline Groups & Dose & MDA/(ìmol/L) & SOD/(IU/mL) \\
\hline Control group & - & $1.106 \pm 0.131$ & $18.782 \pm 2.101$ \\
$\mathrm{H}_{2} \mathrm{O}_{2}$ group & - & $2.327 \pm 0.497^{* *}$ & $7.079 \pm 1.646^{* *}$ \\
North Schisandra Lignans group & $15 \mathrm{mg} / \mathrm{L}$ & $2.011 \pm 0.172$ & $10.325 \pm 1.736$ \\
& $30 \mathrm{mg} / \mathrm{L}$ & $1.853 \pm 0.158^{\# \#}$ & $12.574 \pm 1.852^{\#}$ \\
& $60 \mathrm{mg} / \mathrm{L}$ & $1.546 \pm 0.144^{\# \#}$ & $15.441 \pm 1.931^{\# \#}$ \\
\hline
\end{tabular}

** Compared with control group, $P<0.01$; ${ }^{\#}$ Compared with $\mathrm{H}_{2} \mathrm{O}_{2}$ group, $P<0.05$. ${ }^{\# \#}$ Compared with $\mathrm{H}_{2} \mathrm{O}_{2}$ group, $P<$ 0.01 .

Table 3

Effect of North Schisandra Lignans on ECV-304 cellular supernatant fluid NO content. $(n=3, \bar{x} \pm s)$

\begin{tabular}{lll}
\hline Groups & Dose & NO/(ìmol/L) \\
\hline $\mathrm{Control} \mathrm{group}_{\mathrm{H}_{2} \mathrm{O}_{2} \text { group }}$ & - & $69.231 \pm 4.685$ \\
North Schisandra Lignans group & - & $54.365 \pm 1.328^{* *}$ \\
& $15 \mathrm{mg} / \mathrm{L}$ & $69.589 \pm 2.135$ \\
& $30 \mathrm{mg} / \mathrm{L}$ & $75.354 \pm 2.987^{\#}$ \\
& $60 \mathrm{mg} / \mathrm{L}$ & $81.236 \pm 3.245^{\# \#}$ \\
\hline
\end{tabular}

${ }^{* *}$ Compared with control group, $P<0.01$; ${ }^{\#}$ Compared with $\mathrm{H}_{2} \mathrm{O}_{2}$ group, $P<0.05$; ${ }^{\# \#}$ Compared with $\mathrm{H}_{2} \mathrm{O}_{2}$ group, $P<$ 0.01 .

viously, but SOD content decreased obviously compared with the control group; the difference was significant $(P<0.01)$. Adding $15 \mathrm{mg} / \mathrm{L}, 30 \mathrm{mg} / \mathrm{L}$, or $60 \mathrm{mg} / \mathrm{L}$ North Schisandra Lignans in advance improved SOD content and decreased MDA content. Moderate and high North Schisandra Lignans concentration $+\mathrm{H}_{2} \mathrm{O}_{2}$ displayed a significant difference compared with the $\mathrm{H}_{2} \mathrm{O}_{2}$ group $(P<0.01, P<$ $0.01, P<0.05, P<0.01)$, as shown in Table 2 .

\subsection{Effect of North Schisandra Lignans on ECV-304 cellular supernatant fluid NO content}

$24 \mathrm{~h}$ after being treated by $\mathrm{H}_{2} \mathrm{O}_{2}$ ECV-304 cellular supernatant fluid NO content decreased significantly compared with the control group; the difference was significant $(P<0.01)$. Adding $15 \mathrm{mg} / \mathrm{L}$, $30 \mathrm{mg} / \mathrm{L}$, or $60 \mathrm{mg} / \mathrm{L}$ North Schisandra Lignans in advance improved NO content. Moderate and high North Schisandra Lignans concentrations $+\mathrm{H}_{2} \mathrm{O}_{2}$ displayed significant difference compared with the $\mathrm{H}_{2} \mathrm{O}_{2}$ group $(P<0.05, P<0.01)$, as shown in Table 3 .

\subsection{Effect of North Schisandra Lignans on ECV-304 cellular eNOS expression}

The result of the Western blot showed a specific strap at the molecular weight $133 \mathrm{KD}$ site. $24 \mathrm{~h}$ after being treated by $\mathrm{H}_{2} \mathrm{O}_{2}$, ECV-304 cellular eNOS expression decreased significantly compared with the control group; the difference was significant $(P<0.01)$. Adding $15 \mathrm{mg} / \mathrm{L}, 30 \mathrm{mg} / \mathrm{L}$, or $60 \mathrm{mg} / \mathrm{L}$ of North Schisandra Lignans in advance improved cellular eNOS expression. Moderate and high North Schisandra Lignans concentration $+\mathrm{H}_{2} \mathrm{O}_{2}$ displayed significant differences compared with the $\mathrm{H}_{2} \mathrm{O}_{2}$ group $(P<0.05, P<0.01)$, as shown in Fig. 1 .

\section{Summary}

Atherosclerosis is the pathologic cause of most cardiovascular diseases. Endothelial cell dysfunction is the first step during atherogenesis [13,14]. This leads to endothelial cell dysfunction, further increasing 


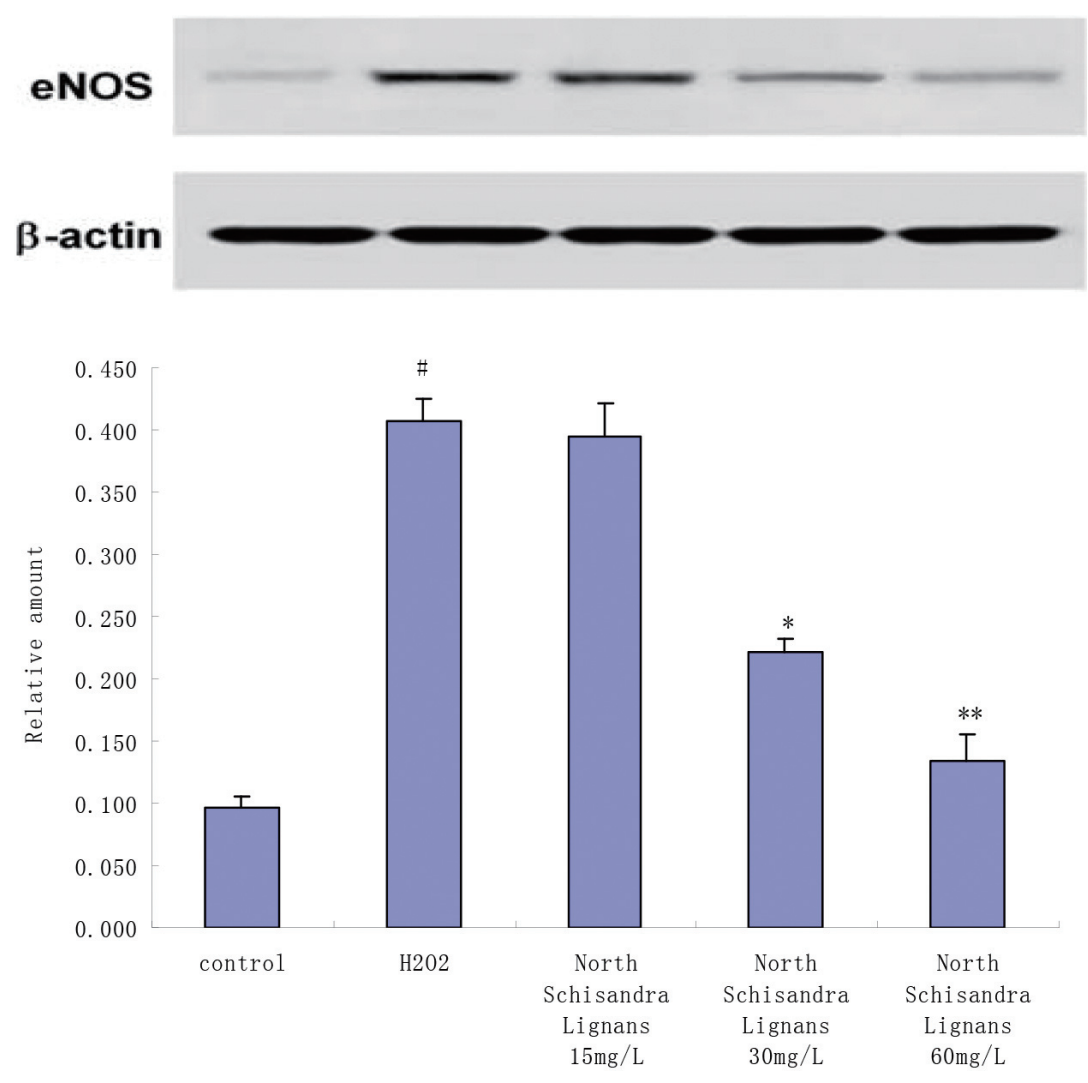

Fig. 1. Effect of North Schisandra Lignans on ECV-304 cellular eNOS expression. ${ }^{*}$ Compared with control group, $P<0.05$; ** Compared with control group, $P<0.01$; ${ }^{\#}$ Compared with $\mathrm{H}_{2} \mathrm{O}_{2}$ group, $P<0.05$.

risk associated with cardiovascular diseases [15]. Many factors can induce endothelial cell dysfunction; oxidative stress plays an important role in cardiovascular disease pathogenesis because it can injure endothelium, inhibit NO production, increase active oxygen (ROS) production, and promote vascular endothelial dysfunction [16]. Currently, there is not a reliable method to detect endothelial dysfunction. $\mathrm{H}_{2} \mathrm{O}_{2}$ is considered a chief component of endothelial dysfunction. Vascular endothelial cellular activity can reflect cellular metabolism and proliferation. Recently, it was proved that the MTT method can be used to study endothelial cellular activity. MTT can be reduced into insolubility amethyst crystallization by succinate dehydrogenase of viable cellular mitochondria and deposit it in cells. However, dead cells do not have this function; thus, this method consensual reflect cytoactive. At a certain cell number, MTT crystallization is a direct ratio to the cell number. Our MTT result shows that North Schisandra Lignans can improve the cytoactivity of ECV-304 treated by $\mathrm{H}_{2} \mathrm{O}_{2}$. It proved that North Schisandra Lignans can promote hydroxy radical production by oxidizing biomacromolecules such as lipid to foment vascular endothelial cellular injury.

$\mathrm{H}_{2} \mathrm{O}_{2}$ can mediate cellular oxidative stress and increase intra-cellular ROS, which attacks various biomacromolecules such as DNA, RNA, protein, fat etc., then causes the alteration of cellular structure and function. Therefore, detecting MDA amounts can show the degree of lipid peroxidation, and further indirectly reflect the degree of cellular injury. Superoxide dismutase (SOD) can reveal the body's anti-oxidative stress system cleaning ROS ability. Our results show that North Schisandra Lignans can 
improve SOD content and decrease lipid peroxidation. This suggests that North Schisandra Lignans has obvious antioxidant capacity.

As oxidative stress plays an important role in atherosclerotic development. Oxidative stress injure vascular endothelium inhibits NO production, which is a kind of endogenous vasodilating factor with doughty vasodilation roles. NO can inhibit ROS production and has an obvious anti-oxidant stress effect. NO is produced through the L-arginine-NO-cGMP passageway, where nitric oxide synthetase (NOS) is the key enzyme. NOS includes cNOS and iNOs; the former also includes the endothelial cell type (eNOS) and cerebral type (nNOS). Being vasodilating, NO is mainly synthesized through eNOS. NO synthesized by eNOS is the most effective endogenous vasodilating agent, which has the roles of rivalry endogenous amidephrine, and inhibits low density lipoprotein oxidation, platelet aggregation, and contractile fiber cellular multiplioation. Our results suggest that North Schisandra Lignans regulates NO production through eNOS.

\section{References}

[1] Shimbo D, Muntner P, Mann D, et al. Endothelial dysfunction and the risk of hypertension: the multi-ethnic study of atherosclerosis.[J]. Hypertension, 2010; 55(5): 1210-1216.

[2] Briasoulis A, Tousoulis D, Androulakis ES, et al. Endothelial dysfunction and atherosclerosis: focus on novel therapeutic approaches.[J]. Recent Pat Cardiovasc Drug Discov, 2012; 7(1): 21-32.

[3] Liu ZY, Kong W. The role of adventitia in atherosclerosis.[J]. Sheng Li Ke Xue Jin Zhan, 2010; 41(3): 177-182.

[4] Rapezzi C, Gallo P. Atherosclerosis: A polidistrectual disease.[J]. G Ital Cardiol (Rome), 2010; 11(12 Suppl 3): 43S-48S.

[5] Albiero M, Menegazzo L, Fadini GP. Circulating smooth muscle progenitors and atherosclerosis.[J]. Trends Cardiovasc Med, 2010; 20(4): 133-140.

[6] Filip M, Maciag J, Nosalski R, et al. Endothelial dysfunction related to oxidative stress and inflammation in perivascular adipose tissue.[J]. Postepy Biochem, 2012; 58(2): 186-94.

[7] Mudau M, Genis A, et al. Endothelial dysfunction; the early predictor of atherosclerosis.[J]. Cardiovasc J Afr, 2012; 23(4): 222-31.

[8] Davignon J, Ganz P. Role of endothelial dysfunction in atherosclerosis.[J]. Circulation, 2004; 109(23 Suppl 1): III27-32.

[9] Lakshmi SV, Padmaja G, et al. Oxidative stress in cardiovascular disease.[J]. Indian J Biochem Biophys, 2009; 46(6): 421-40.

[10] Park JQ, Oh GT. The role of peroxidases in the pathogenesis of atherosclerosis.[J]. BMB Rep, 2011; 44(8): 497-505.

[11] Gao S, Liu Z, Li H, et al. Cardiovascular actions and therapeutic potentialof tanshinone IIA.[J]. Atherosclerosis, 2012; 220(1): 3-10.

[12] Davignon J, Ganz P. Role of endothelial dysfunction in atherosclerosis.[J]. Circulation, 2004; 109(23 Suppl 1): III27-32.

[13] Karatzis EN. The role of inflammatory agents in endothelial function and their contribution to atherosclerosis.[J]. Hellenic J Cardiol, 2005; 46: 232-239.

[14] Vita JA. Endothelial function and clinical outcome.[J]. Heart, 2005; 91: 1278-279.

[15] Higashi Y, Noma K, et al. Endothelial Function and Oxidative Stress in Cardiovascular Diseases.[J]. Circ J, 2009; 73 : 411-418.

[16] Stirban A. The role of AGEs and ROS in atherosclerosis.[J]. Herz, 2010; 35(3): 170-180.

[17] J Biol Chem, 2011; 286(41): 36011-9. doi: 10.1074/jbc.M111.265082. Epub 2011 Aug 24

[18] J Biol Chem, 2013; 288(17): 11940-8. doi: 10.1074/jbc.M112.427674. Epub 2013 Mar 18. 